\title{
Archéopages
}

Archéopages

Archéologie et société

38 | 07/2013

Terres inhospitalières

\section{Plantation d'asperges dans la plaine du Forez. Une culture dans le contexte fluvial actif de la Loire}

\section{Vincent Georges}

\section{(2) OpenEdition}

1 Journals

Édition électronique

URL : https://journals.openedition.org/archeopages/487

DOI : 10.4000/archeopages.487

ISSN : 2269-9872

Éditeur

INRAP - Institut national de recherches archéologiques préventives

Édition imprimée

Date de publication : 1 août 2014

Pagination : 6-11

ISSN : 1622-8545

\section{Référence électronique}

Vincent Georges, «Plantation d'asperges dans la plaine du Forez. Une culture dans le contexte fluvial actif de la Loire », Archéopages [En ligne], 38 | 07/2013, mis en ligne le 01 juillet 2015, consulté le 22 janvier 2022. URL : http://journals.openedition.org/archeopages/487 ; DOI : https://doi.org/10.4000/ archeopages. 487 


\section{Plantation d'asperges dans la plaine du Forez Une culture dans le contexte fluvial actif de la Loire}

Vincent Georges Inrap, UMR 6298 «Archéologie, Terre, Histoire, Sociétés»

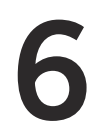

1. O. Franc, Andrézieux Bouthéon, Les BéallièresSud. Sondages de diagnostic archéologique, Rapport final d'opération archéologique, Inrap Drac Rhône-Alpes, 2003.
L’archéologie préventive a récemment bien mis en évidence les traces agraires laissées par les cultures d'asperges (Billoin, Dufour, 2005). Il est ici question de présenter des conditions d'implantation inédites en situation d'espace fluvial. Ce milieu est réputé difficile en raison des dommages pouvant survenir lors des crues à fort débit : un diagnostic réalisé dans l'extrême sud de la plaine du Forez a ainsi permis de comprendre le développement d'une culture maraîchère soumise à un contexte fluvial actif et instable.

\section{Caractéristiques topographiques et stratigraphiques}

Le profil pentu du bassin amont ligérien renforce les crues à caractère catastrophique capables d'emporter des ponts durant le Moyen Âge, comme ce fut encore le cas en 1680 ou en 1907 (Champion, 1856 ; Jollois, 1881 ; Georges et al., 2004). L'aggravation des crues durant le Petit Âge Glaciaire se traduit par un élargissement de la bande de divagation historique du lit mineur ligérien (Cubizolle, Georges, 2001). Ce fonctionnement fluvial mobilise des charges sablo-graveleuses considérables et concourt à reconfigurer la topographie par épisodes successifs comme pour le Rhône (Bravard, 1989). En réaction à ce fonctionnement, l'endiguement de la Loire dans le bassin du Forez, au demeurant très partiel du XVIII ${ }^{\mathrm{e}}$ jusqu'au début du $\mathrm{Xx}^{\mathrm{e}}$ siècle, visait à canaliser le lit mineur tout en protégeant les terres agricoles des plaines d'inondation (Degorce, 1995).

Les sondages profonds menés sur le site des Béallières, à Andrézieux-Bouthéon, soulignent l'intensité du fonctionnement fluvial aux époques historiques. Un tronc d'aulne piégé dans une couche sablo-graveleuse [ill. 1] et préservé par la nappe phréatique fournit un précieux terminus post quem via une datation par calibration $\mathrm{du}_{\mathrm{C}} \mathrm{C}_{4}$ :
Lyon-2324 (Poz), 1177-1283 cal. AD. Il est à noter que le pont de Rivas, situé à quelques kilomètres à l'aval, est mentionné pour la dernière fois dans des textes datés de 1280 (Dufour, 1946). Des tessons épars

de céramiques vernissées apportent des indices concordant avec la donnée archéométrique obtenue sur le bois d'aulne. Les sédimentations à charges grossières comprises entre trois et quatre mètres de profondeur sont donc récentes et se sont probablement formées au début du Petit âge glaciaire ; l'étude géomorphologique menée par Odile Franc ${ }^{\mathbf{1}}$ a permis d'identifier des charriages de crues de grande ampleur en rapport avec les épaisses strates sableuses qui les recouvrent. Cependant cette date unique, qui porte sur du bois flotté potentiellement remanié, a tendance à reculer le début du Petit âge glaciaire et peut être le fait d'une crue événementielle.

Ces dépôts grossiers sont recouverts d'horizons supérieurs à sédimentation plus fine qui datent de la fin du Moyen Âge ou d'une période plus récente encore.

Dans cette phase de colmatage par décantation, là où des horizons limoneux suffisamment épais se sont constitués, des cultures d'asperges ont été installées [ill. 2 : sondages en noir]. Le remplissage des sillons (larges d'environ $60 \mathrm{~cm}$ et profonds de 35 à $40 \mathrm{~cm}$ ) destinés à recueillir les plans se compose de sables sans litages, prélevés sur berge ou apportés lors de crues. La forte présence de charbon minéral roulé prouve que les sables proviennent pour une bonne part des alluvions du Furan qui afflue en rive droite, à un kilomètre à l'amont, après avoir traversé le bassin minier de Saint-Étienne. Le sable a une valeur agronomique primordiale pour la production d'asperges qui prospère en zones humides ou irriguées. La plaine d'inondation, 


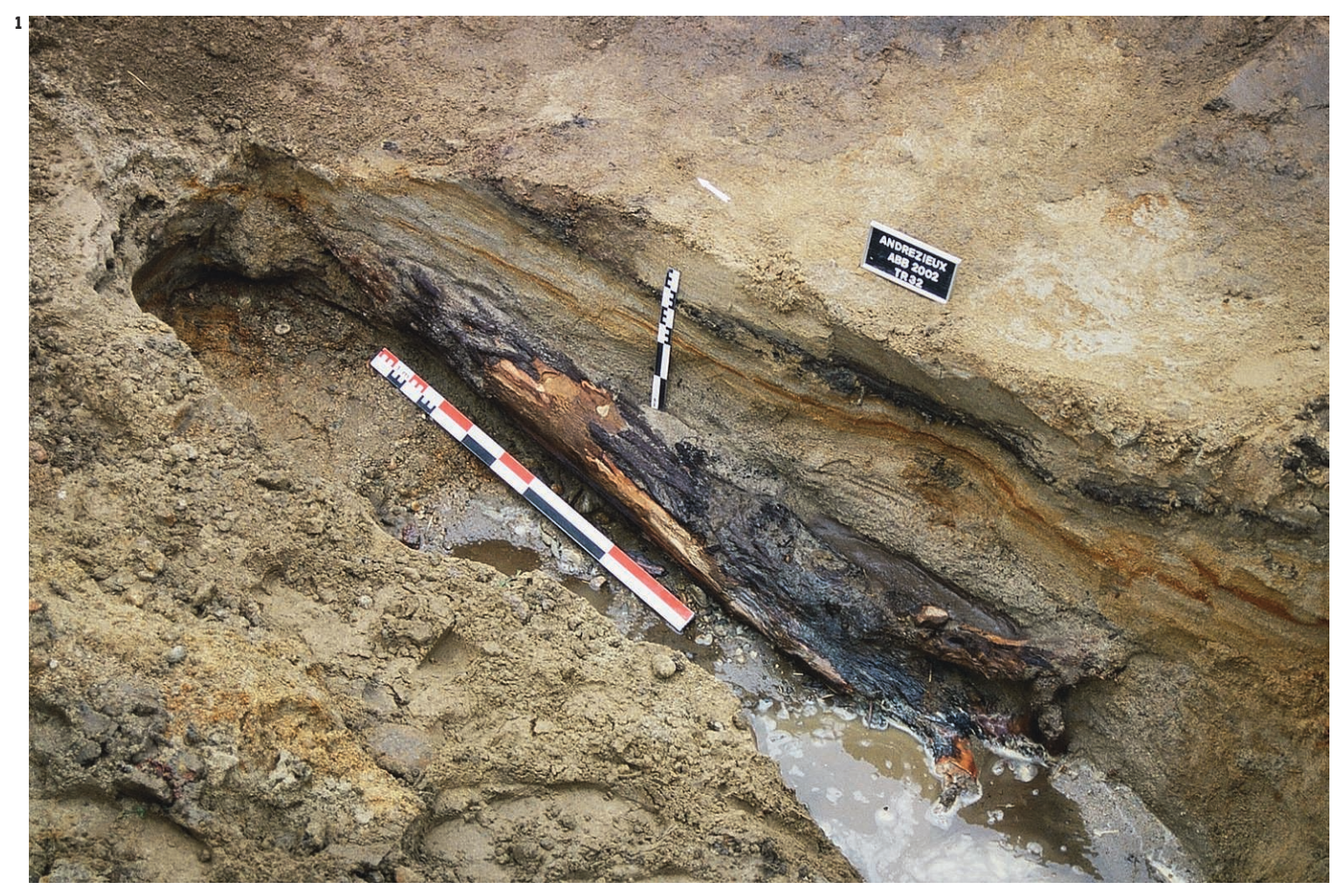

1. Tronc d'aulne déposé dans un épandage sablo-graveleux

2. Contexte du lit majeur au

début des années 2000 en

zone périurbaine avec le

positionnement des

sondages sur le fonds

cadastral (d'après www.

cadastre.gouv.fr, modifié). En

noir : sondages avec traces

agraires; en gris : absence de

traces agraires; en rouge

sondage 46.

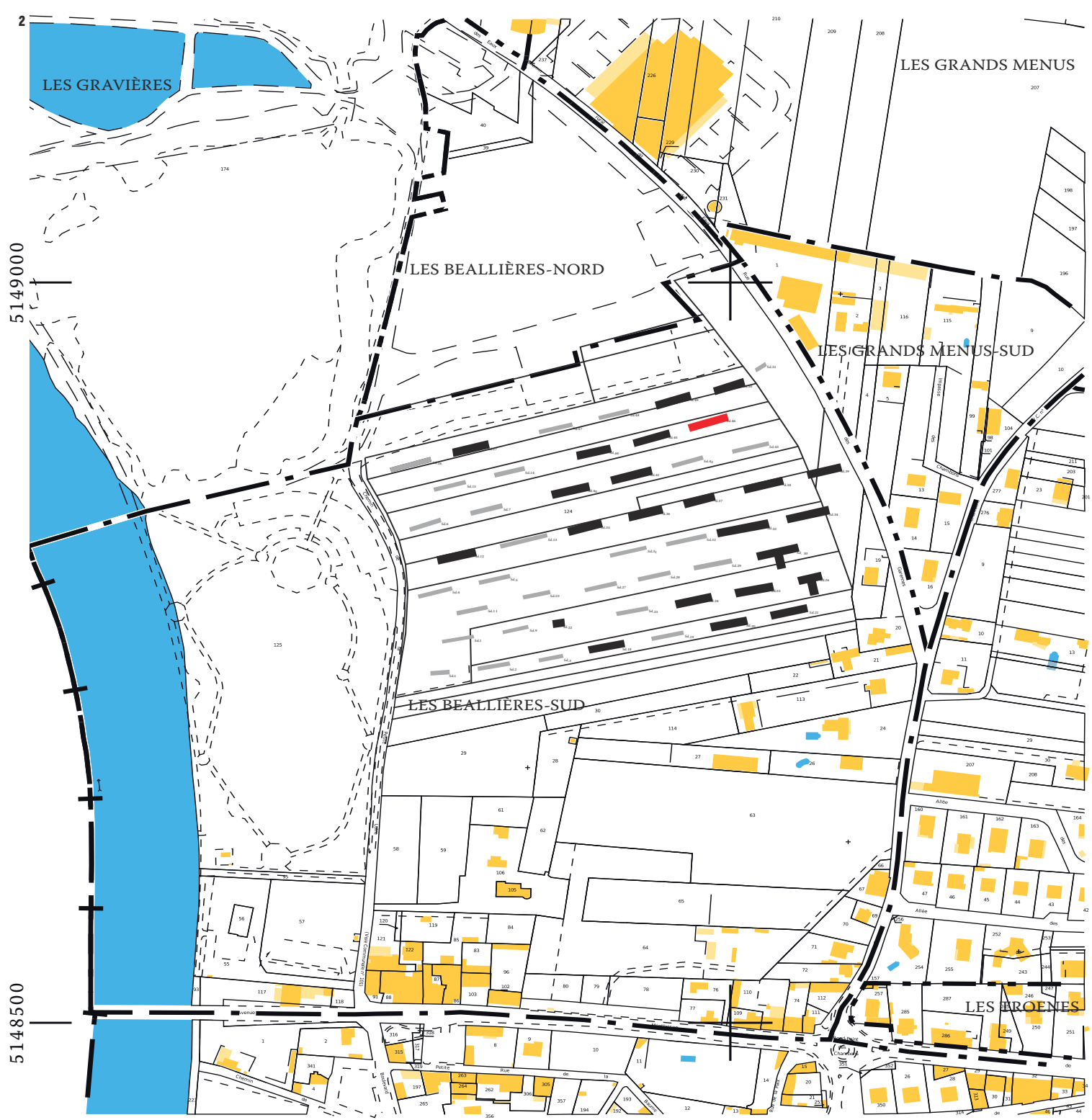

$\stackrel{N}{\Lambda}$ 


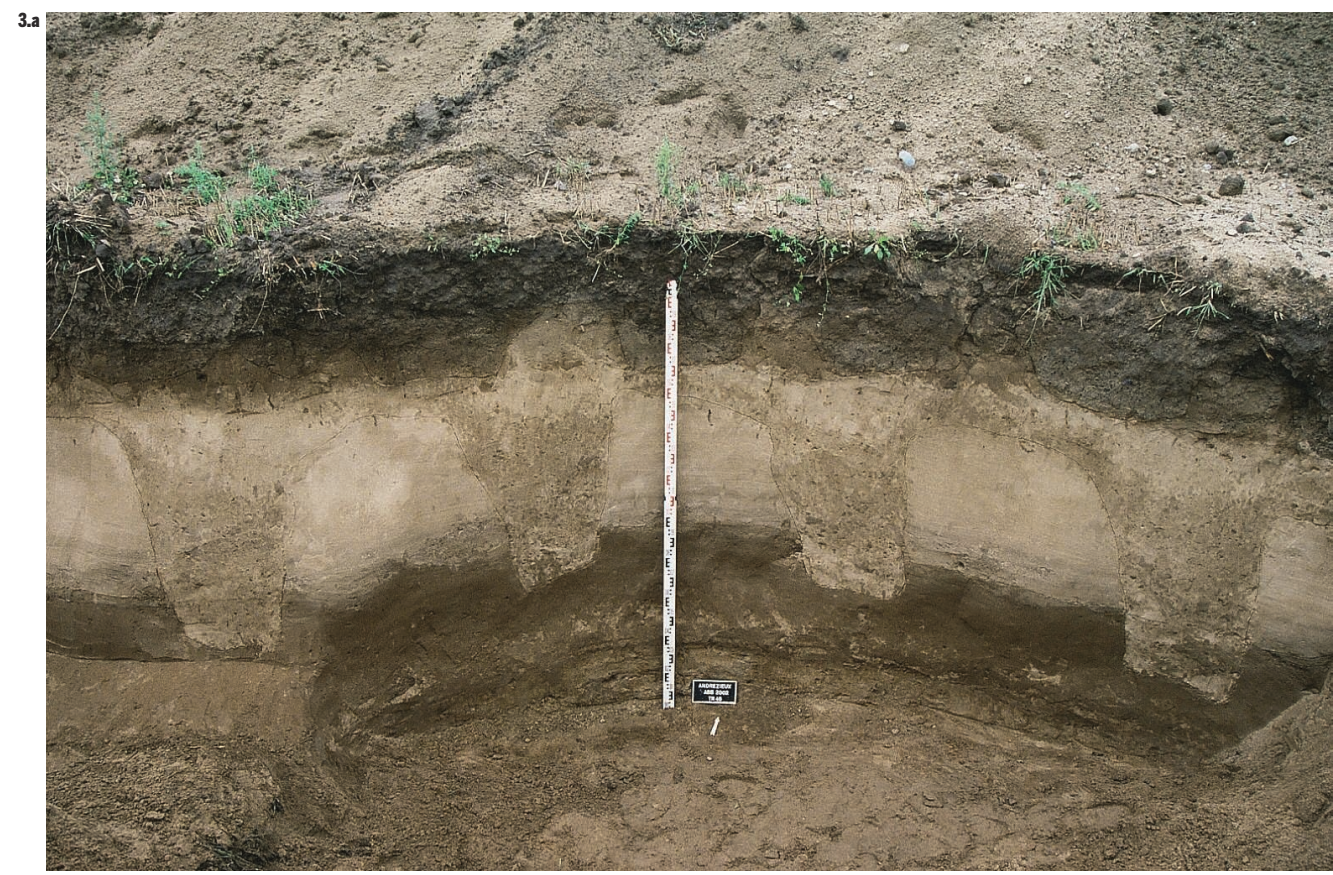

3. a. Coupe stratigraphique du sondage 46 avec détail du litage (3.b.).

4. Le contexte des strates

limoneuses ayant servi

à implanter les cultures

d'asperges dans

le sondage 46.

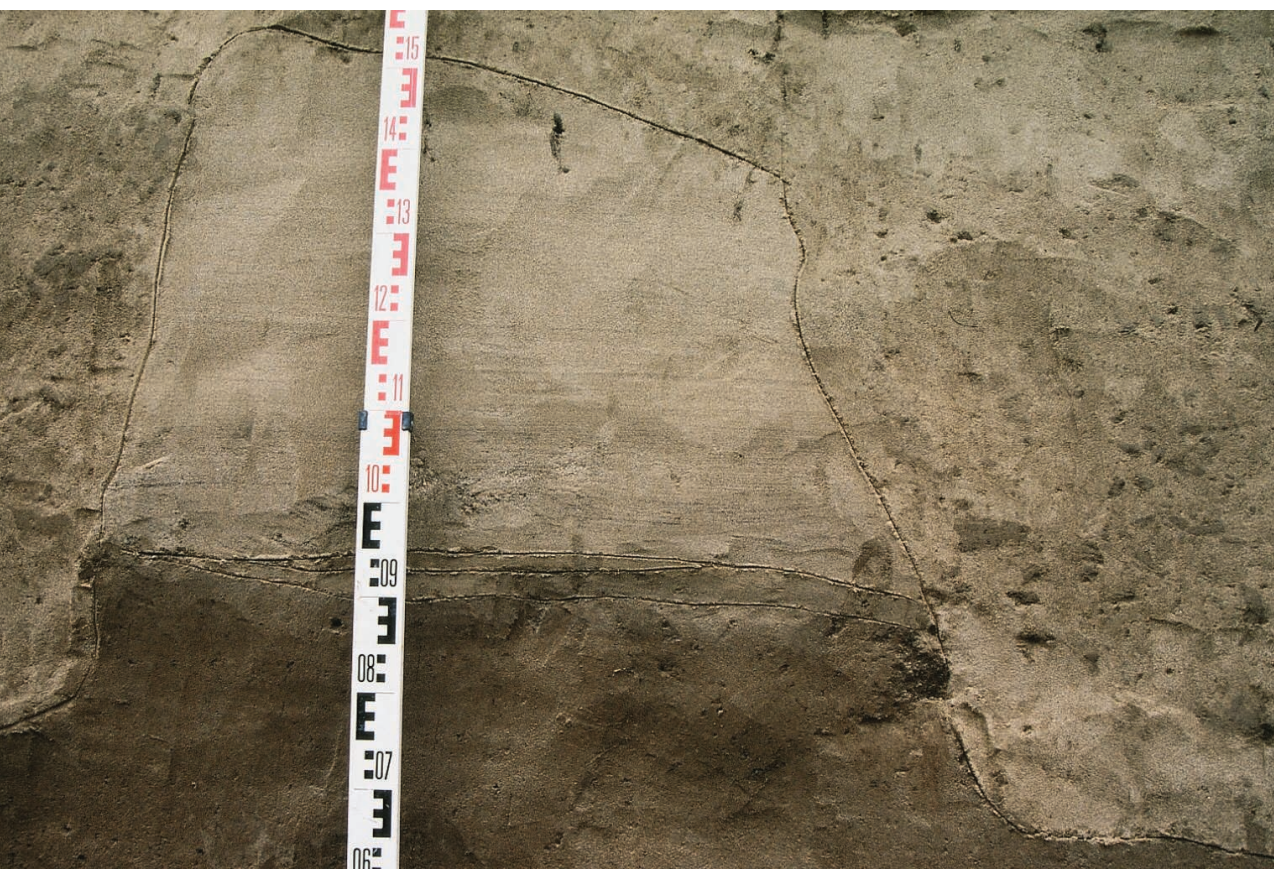

S ondage 46

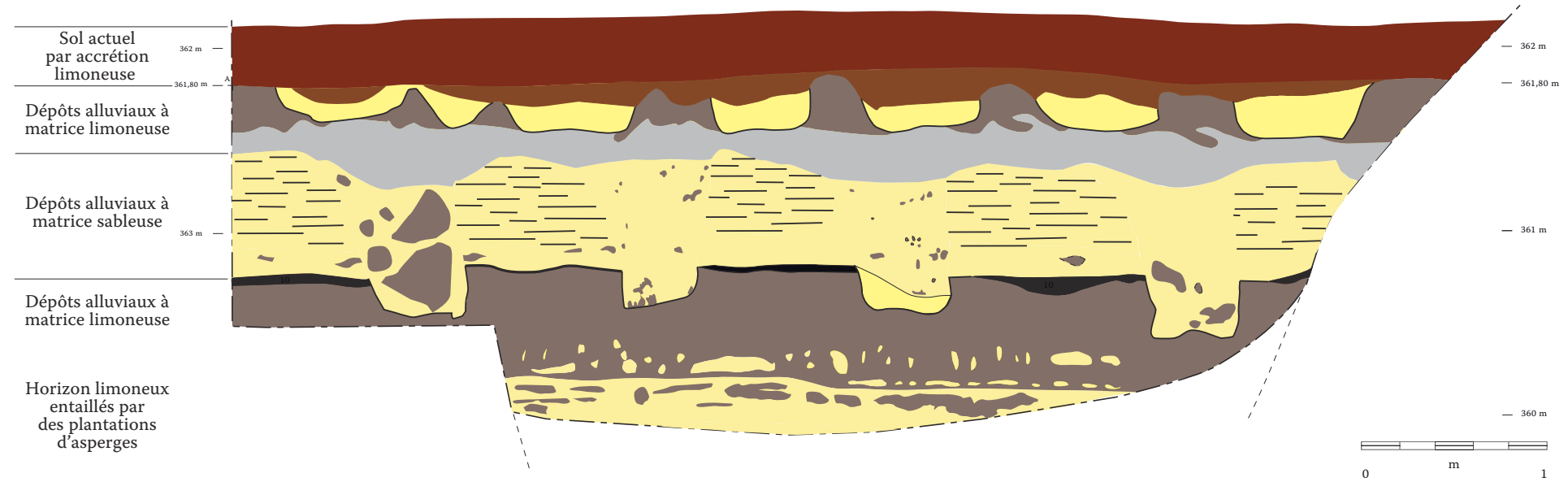


naturellement humide, permet par ailleurs de creuser les sillons dans les sédimentations fines supérieures dotées d'une aptitude à retenir l'eau et à compenser l'évapotranspiration des strates sableuses.

Ces sillons restent la plupart du temps subaffleurants sous l'horizon cultural actuel. Toutefois, au niveau du sondage 46 [ill. 2 : sondage en rouge], on observe un étagement des sillons dans la zone dépressionnaire orientale héritée du Würm. L'empilement sédimentaire de la dépression imperceptible dans la topographie actuelle [ill. 3 et 4] enregistre à cet endroit deux plantations successives séparées par un dépôt sableux d'alluvions. Le niveau inférieur des sillons est recouvert par un épais banc sableux. Un litage fin et homogène des sables est présent sur toute la séquence et ce, uniquement à intervalles réguliers entre les sillons. Les courants d'eau ont ainsi simultanément charrié des mottes de limon et du sable dans l'axe des creusements d'une part, et déposé des litages collatéraux d'autre part. Les indices de piétinement sous-jacents entre les sillons témoignent à leur manière d'un premier état implanté dans un substrat limoneux comme partout ailleurs sur le reste des plantations. Le recouvrement sableux ultérieur provoque son enfouissement définitif. Une nouvelle génération de sillons à remplissage limono-sableux sombre vient coiffer cette séquence alluviale.

La stratigraphie indique donc bien deux phases d'exploitation successives séparées par des dépôts sédimentaires. Un dernier horizon sédimentaire vient sceller la séquence sous la forme de dépôts limoneux superficiels constitutifs du sol moderne.

La mise en évidence de ces deux phases démontre qu'un écoulement fluvial provoquant un ensablement massif n'a pas été fatal à une activité agraire bien spécifique et demandant des aménagements importants. Ce choix socioéconomique, relatif à une exploitation sinon à plusieurs productions distinctes en zone d'inondation, donne matière à réfléchir sur l'efficience de la notion de terroir à risques. Si ceux-ci sont intégrés au processus d'exploitation, il ne s'agit plus alors que d'une spécificité territoriale rentrant en ligne de compte. L'impact des crues imprévisibles, seulement dévastatrices au plus fort des courants, doit du même coup être relativisé. Par ailleurs, dans ce cas précis, un aspect bénéfique des crues est la formation d'une strate limoneuse discontinue où les sillons ont pu être implantés [ill. 5].

\section{Contexte des vestiges confronté aux archives}

La consultation des archives apporte des données complémentaires en mesure d'attribuer les vestiges de culture d'asperges à une période antérieure au XIX ${ }^{\mathrm{e}}$ siècle. En effet, le premier cadastre relevé date de 1811 et induit que la plantation appartient sans nul doute à une époque antérieure. Il est certain que les limites d'extension des sillons ne coïncident pas avec le dispositif en lanières est-ouest du XIX ${ }^{\mathrm{e}}$ qui a perduré jusqu'au $\mathrm{xx}^{\mathrm{e}}$ siècle. Les sillons doivent par ailleurs être orientés nord-sud avec un talutage au niveau de leur interstice pour préserver les plans d'asperges de l'ensoleillement (Billoin, Dufour, 2005) ${ }^{2}$. La limite entre deux lots de sillons perçus dans le sondage 30 est suffisamment décalée de la limite de parcelle de 1811 pour souligner deux parcellaires distincts [ill. 6].

Des propriétaires urbains indépendants sont mentionnés dans les registres d'État du XIX ${ }^{\mathrm{e}}$ siècle, qui, pour la plupart, ne résident pas dans la commune. On y apprend surtout que seules les parcelles occidentales, bien à la marge des traces archéologiques de sillons, ont fait l'objet d'un changement de statut fiscal en raison de crues ayant rendu les terrains incultes. Une couche de sable superficielle a ainsi livré une plaque en alliage cuivreux portant le nom de Louis Coquetier, attribuable au XIX ${ }^{\mathrm{e}}$ siècle, sur la marge occidentale des indices de plantation. Ces dépôts dévastateurs sont en lien avec un ancien bras noté comme actif sur le relevé cadastral effectué en 1811 et situé au nord-ouest du diagnostic archéologique. Les habitants s'inquiètent de la réactivation de ce bras mort jusqu'en 1905 alors que cette annexe fluviale est pourtant déconnectée par un endiguement (Degorce, 1995, p. 110). Les parcelles rendues incultes au XIX ${ }^{\mathrm{e}}$ siècle se situent donc dans un contexte particulier, en marge occidentale de la plantation d'asperges. D'après les archives consultées, ce dernier secteur est plus que vraisemblablement resté préservé des ensablements au XIX ${ }^{\mathrm{e}}$ siècle. Ajoutons à cela que, sur l'ensemble des sondages, la profondeur des sillons est homogène. Une minorité de sondages a permis de localiser des sillons arasés. Il faut donc prendre en ligne de compte le dépôt de 30 à $40 \mathrm{~cm}$ de sédimentation fine après l'abandon de cette culture qui apparaît effectif dès le $\mathrm{XIX}^{\mathrm{e}}$ siècle.

D'autre part, les sondages qui ne comportent pas de traces de sillons ne présentent pas non plus les strates limoneuses adéquates et nécessaires [ill. 2 : sondages en gris]. L'existence de ces dernières a guidé l'implantation des plantations en dehors d'une logique parcellaire stricte.

Avant la Révolution française, les données archivistiques sont moins précises. Un terrier de 1751 renseigne toutefois sur la propriété foncière environnant le château de Bouthéon situé à un peu plus d'un kilomètre au nord des sondages (Lejeune et al., 2004). Le Domaine de Basse-cour, dont il est fait mention dans ce document ${ }^{3}$, concerne très probablement la très fertile plaine d'inondation ligérienne surplombée par le château. Sans pouvoir attribuer les plantations d'asperges à ce domaine du XVIII ${ }^{\mathrm{e}}$ siècle, sa proximité rend l'hypothèse crédible.

Avec plus de certitude, le microtoponyme Les Béallières, un dérivé de « Béal », synonyme de bief (Gras, 1863), renvoie tacitement aux sillons parallèles et à fond plat de l'aspergerie, par analogie avec les canaux de moulin. Malheureusement, on ne possède aucun indice antérieur au XIX ${ }^{\mathrm{e}}$ siècle 


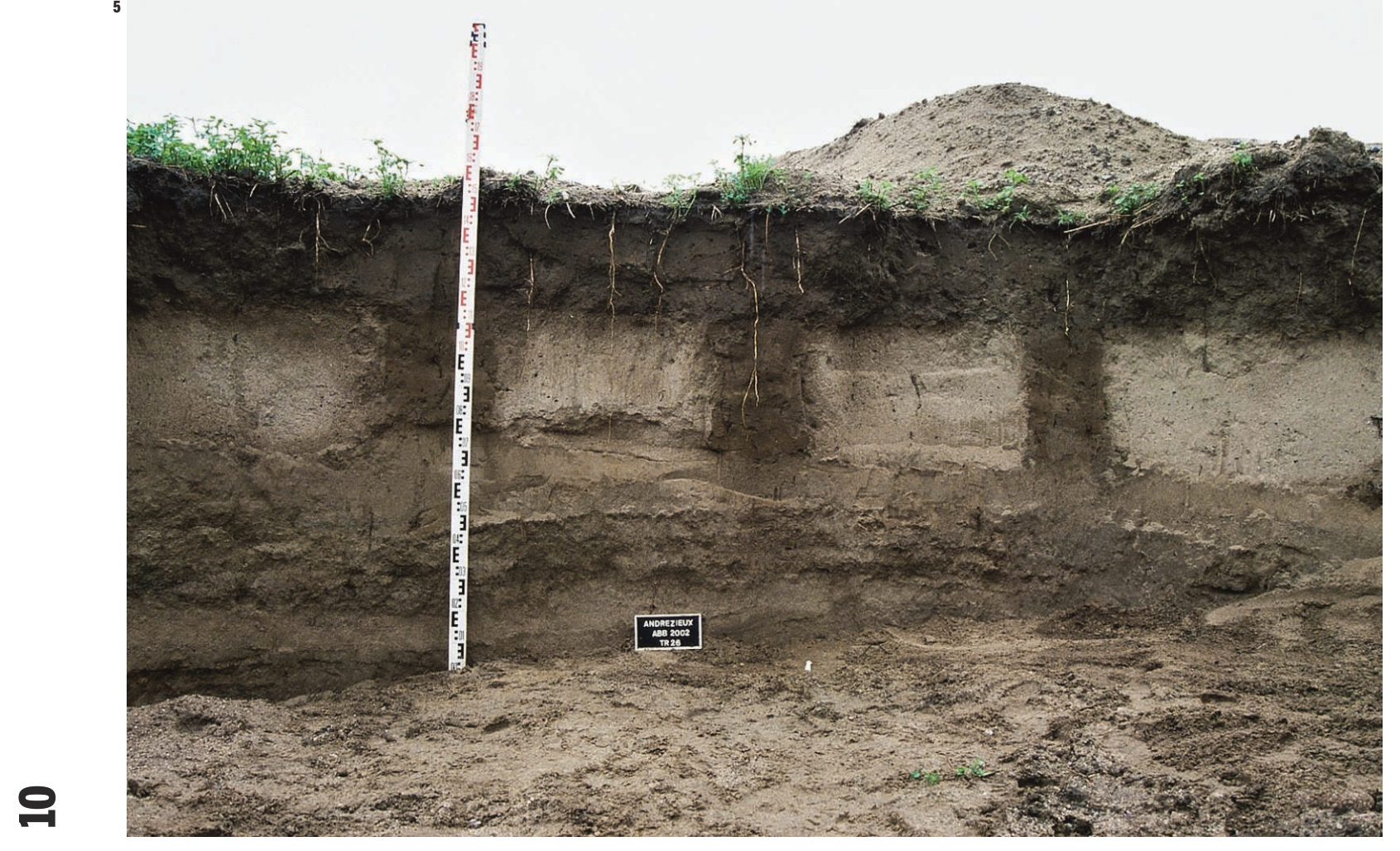

5. Détail de sillons sur coupe

stratigraphique (sondage

26): les crues ont formé une

strate limoneuse dans

laquelle ont pu être

implantés des sillons.

6. Détail d'une partition de

sillons parallèles en deux lots

contigus (sondage 30 ).

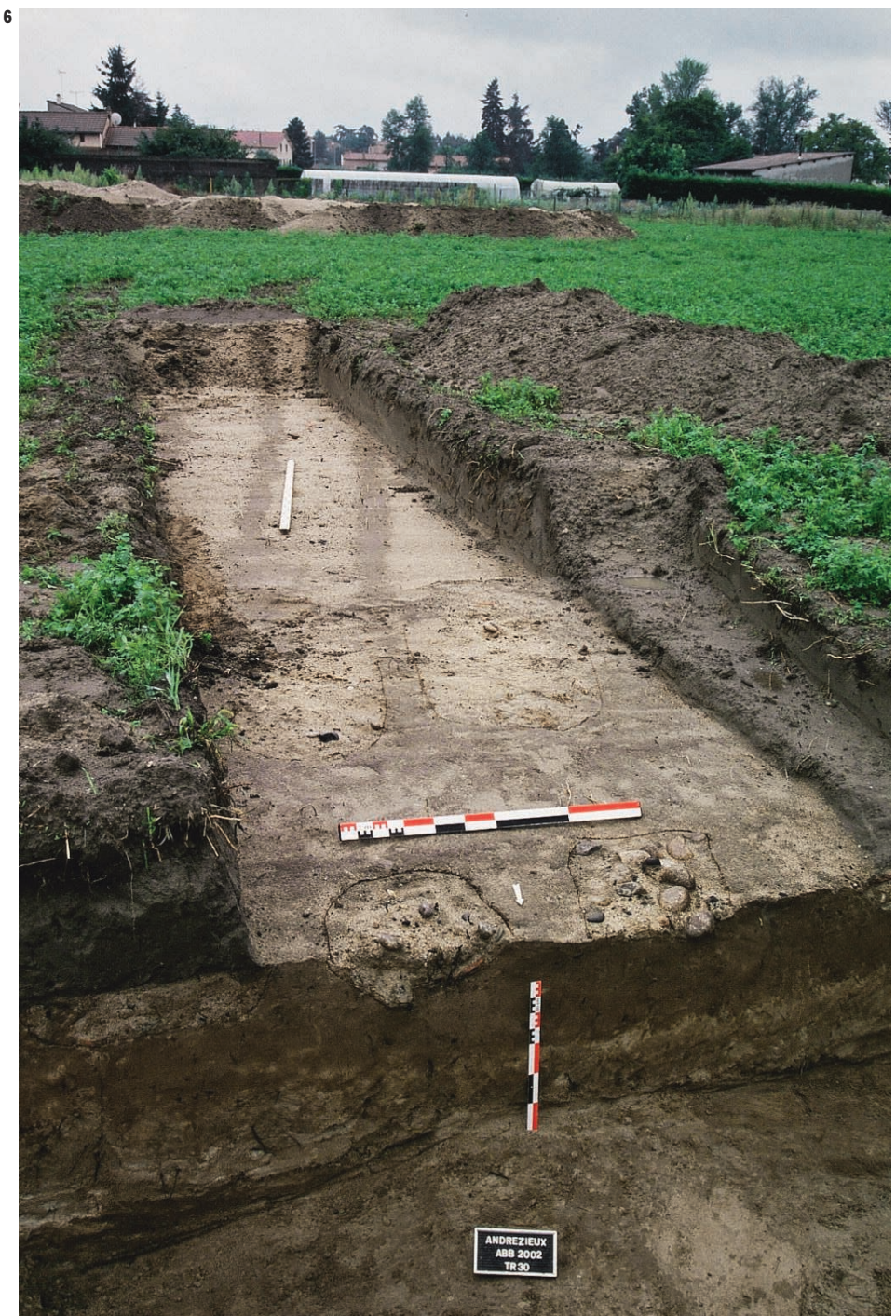


pour ce toponyme très localisé.

Une autre source rédigée en lien avec le château (mais sans mention de cette culture) renseigne de façon détaillée sur les revenus de la seigneurie au moment de l'acquisition du château de Bouthéon par Guillaume de Gadagne en 1561, après que sa famille eut été chassée de Florence par les Médicis. À partir de cette date, la gestion du domaine est entre les mains d'une grande puissance financière de l'Ancien Régime établie à Lyon, qui tire sa fortune du commerce entre l'Italie et le Royaume de France $\mathrm{du} \mathrm{XVI}{ }^{\mathrm{e}}$ au XVIII ${ }^{\mathrm{e}}$ siècle. Gageons que des recherches ultérieures aux archives pourraient préciser la stratégie domaniale dans l'environnement du château de Bouthéon. Entre le milieu du Xvi ${ }^{\mathrm{e}}$ et celui du XVIII ${ }^{\mathrm{e}}$ siècle, le domaine passe, d'après les documents précités, de 150 à 650 hectares.

\section{Stratégie économique durable}

Selon les indices recueillis, la production d'asperges remonte très probablement à l'Ancien Régime. Le caractère lucratif de cette récolte maraîchère, non soumise à l'impôt royal, a pu rendre supportable la délicate et imprévisible cohabitation avec les crues du fleuve, sans compter les deux ans de latence avant les premiers rendements (Billoin, Dufour, 2005). À cela s'ajoute la proximité de Saint-Étienne et de Lyon et d'autres centres de consommation de moindre importance. La navigation marchande sur la Loire, qui débute ici son périple en direction du nord jusqu'à Paris via Roanne et Orléans, a pu également servir de débouché (Luya, 1991). La vaisselle spécialisée dans la consommation d'asperges au XIX ${ }^{\mathrm{e}}$ siècle prouve l'importance acquise par ce légume dans la palette des pratiques culinaires après la Révolution (Arminjon, Blondel, 2006).

Pour ce qui est de la culture de l'asperge, l'investissement nécessaire peut expliquer qu'elle soit l'apanage de grands domaines ou de zones très spécialisées à proximité de centres de consommation (ibid.). Une aspergerie doit être déplacée tous les 12 à 25 ans pour des raisons d'épuisement des sols (ibid.). L'espace disponible nécessaire peut être avantageusement gagné sur des terres réputées inondables et donc favorablement humides, potentiellement prises à la ripisylve dont un balisage de la Loire en 1732 montre la vigueur du biotope (Gardon, 2010). L'extension des plantations, comprise entre un à deux hectares, souligne le caractère pérenne de l'exploitation des Béallières. Malgré des crises hydrologiques épisodiques, l'intégration environnementale est demeurée favorable au maintien du dispositif agronomique
Références bibliographiques

CHAMPION M., 1856 : Recherches historiques sur les inondations du Rhône et de la Loire, Paris, Typographe Panckoucke, 19 p. [Extrait du Moniteur officiel du 20 juillet 1856]

Dufour J.-E., 1946 : Dictionnaire topographique $d u$ Forez et des paroisses du Lyonnais et du Beaujolais formant le département de la Loire, Mâcon, impr. Protat Frère, 1184 p.

Gras L.-P., 1863 : Dictionnaire du patois forézien, Lyon, A. Brun, $270 \mathrm{p}$.

Jollois M., 1881 : Mémoire sur les crues de la Loire supérieure, in Annales des Ponts et Chaussées, $1^{\text {er }}$ semestre, p. 273-322.

Arminjon C., Blondel N., 2006 : Objets civils domestiques. Vocabulaire typologique. Inventaire général des monuments et des richesses artistiques de la France, Paris, éd. du Patrimoine, p. 90-91.

Billoin D., Dufour J.-Y., 2005 : « La reconnaissance archéologique des cultures maraîchères anciennes: l'exemple des aspergeries », Archéopages, $\mathrm{n}^{\circ}$ 15, p. 12-15.

BRAVARD J.-P., 1989 : «La métamorphose des rivières des Alpes françaises à la fin du Moyen Âge et à l'époque moderne », Bulletin de la Société de géographie de Liège, $\mathrm{n}^{\circ}$ 25, p. 145-157.

Cubizolle H., Georges V., 2001 : «L'évolution holocène de la plaine alluviale de la Loire dans le bassin du Forez (Massif central, France). Mise en évidence du potentiel géoarchéologique », Quaternaire, 12, p. 53-67.
DegorCE J.-N., 1995 : Les milieux humides dans la Loire, Saint-Étienne, Publications de l'université de Saint-Étienne, 377 p.

GARDON N., 2010 : « Procès-verbal du balisage de la Loire en 1732 », Bulletin de la Diana, t. 69, $\mathrm{n}^{\circ} 4$, p. 295-320.

GASCON R., 1971: Grand commerce et vie urbaine au XVI $I^{e}$. Lyon et ses marchands, Paris, SEVPEN, 2 vol., 999 p.

Georges V., Franc O., 2003: Andrézieux-Bouthéon, Les Béallières-Sud. Sondages de diagnostic archéologique, Rapport final d'opération archéologique, Inrap - Drac Rhône-Alpes, 22 p.

Georges V., Cubizolle H., Argant J. et al., 2004 «Détection, détermination et interprétation des témoins archéologiques de la Loire en Forez (Massif central, France) : vers une histoire du peuplement », in BURNouf J. et LeVEAu P. (DIR.), Fleuves et marais, une histoire au croisement de la nature et de la culture. Sociétés préindustrielles et milieux fluviaux, lacustres et palustres : pratiques sociales et hydrosystèmes, Paris, éd. du CTHS, p. $71-83$.

Lejeune E., Meras M., Blazy S., 2004 : La saga lyonnaise des Gadagne, Lyon, Éditions lyonnaises d'art et d'histoire, $173 \mathrm{p}$.

LUYA D., 1991 : Navigation et commerce sur la Loire dans son cours supérieur, Saint-Étienne,

Organisation pour la publication de travaux d'intérêt scientifique (Opus), 220 p. 